\title{
Magnetic hysteresis and crystallization studies on metallic glass alloy $\mathrm{Fe}_{67} \mathrm{Co}_{18} \mathrm{~B}_{14} \mathrm{Si}_{1}$
}

\author{
A M VARAPRASAD and C RADHAKRISHNAMURTHY* \\ Naval Chemical and Metallurgical Laboratory, Naval Dockyard, Bombay 400023 , India \\ *Tata Institute of Fundamental Research, Bombay 400 005, India
}

MS received 10 February 1986; revised 21 May 1986

\begin{abstract}
Magnetic hysteresis studies were carried out on Metglas $2605 \mathrm{Co}\left(\mathrm{Fe}_{67} \mathrm{Co}_{18} \mathrm{~B}_{14} \mathrm{Si}_{1}\right)$ samples, cut parallel and perpendicular to the ribbon axis and annealed at different temperatures. The samples annealed at $450^{\circ} \mathrm{C}$ for $2 \mathrm{hr}$ show a coercive force of $8.75 \mathrm{Oe}$ and $0.60 \mathrm{Oe}$ in the parallel and perpendicular directions respectively. Electron probe micro analysis studies revealed the onset of primary crystallization at $400^{\circ} \mathrm{C}$ and a gradual displacement of $\mathrm{B}$ and $\mathrm{Si}$ from the lattice as the annealing temperature was increased to $450^{\circ} \mathrm{C}$. The observed large coercive force is due to an increase in anisotropy resulting from an intergrowth pattern of the type $\mathrm{Fe}_{x} \mathrm{Co}_{1-x}, 0.3<x<1.0$, including boron containing phases such as $(\mathrm{FeCo}) \mathrm{B},(\mathrm{FeCo})_{2} \mathrm{~B},(\mathrm{FeCo})_{3} \mathrm{~B}$, developed by the displacement of and $\mathrm{Si}$ from the original amorphous lattice.
\end{abstract}

Keywords. Amorphous alloys; anisotropy; crystallization; magnetic hysteresis.

\section{Introduction}

Recently, amorphous alloys have emerged as a new class of materials for constituting high performance transducers and sensors: Both isotropic and anisotropic properties of amorphous alloys find applications in device construction (Mohri 1984; Sasada et al 1984). The material under study, commercially known as Metglas $2604 \mathrm{Co}$ with the composition $\mathrm{Fe}_{67} \mathrm{Co}_{18} \mathrm{~B}_{14} \mathrm{Si}_{1}$, has a high magnetostriction constant $\left(\lambda=35 \times 10^{-6}\right)$ (Allied 1981) coupled with a higher saturation induction and is suitable for underwater transducer applications (Mohri 1984). The magnetic properties of this material could be conveniently modified by adopting suitable annealing procedures. The magnetic hysteresis properties, crystallization aspects and its relation to magnetic anisotropy of this material annealed to different temperatures have been reported in this paper.

\section{Experimental}

Metglas 2605 Co ribbon, $50 \mathrm{~mm}$ wide, $27 \mu$ thick (supplied by Allied Corporation, USA) was cut into strips of dimensions $50 \mathrm{~mm} \times 4 \mathrm{~mm}$ and of equal weight, both parallel and perpendicular to the ribbon axis. These were annealed at 100, 200, 300, 400 and $450^{\circ} \mathrm{C}$ for a constant period of $2 \mathrm{hr}$.

Hysteresis studies were carried out on the strip samples using a hysteresis loop tracer (Radhakrishnamurthy et al 1978) suitably modified to minimize the demagnetization effects. The coercive force $H_{c}$ measured on the original sample is $0.08 \mathrm{Oe}$, which corresponds well with the value given in the specification of this material. The crystallization and composition analysis were carried out using an 
electron probe micro analyser (model:Camebax, Chemica, France) (Beaman and Isasi 1972). Phase analysis, if any, was carried out using a Siemens Kristalloflux x-ray diffractometer. The statistical data on the crystallite dimensions were obtained using a TAS plus image analyser.

\section{Results and discussion}

Figures 1 (a) to (f) depict the hysteresis of the Metglas samples taken parallel to the ribbon axis and annealed for $2 \mathrm{hr}$ at temperatures (a) as obtained, (b) $100^{\circ} \mathrm{C}$, (c) $200^{\circ} \mathrm{C}$, (d) $300^{\circ} \mathrm{C}$, (e) $400^{\circ} \mathrm{C}$ and (f) $450^{\circ} \mathrm{C}$. The hysteresis loops for samples taken perpendicular to ribbon axis are shown in figures 2 (a) to (f). The $H_{c}$ data are presented in table 1.

From figures 1 (a) and 2(a) a slight difference is seen in the $H_{c}$ of the original sample in either direction. It can be inferred, therefore, that the starting samples possess little anisotropy due to magnetostriction and/or magnetoelastic effects (Haregawa 1976; Suja et al 1975; Takahashi et al 1976). Samples annealed at $400^{\circ} \mathrm{C}$ have shown clusters of tiny crystallites (figure 3a), without a significant change in the magnetic hysteresis (figures 1e and 2e). The crystallite dimensions range from a few hundred to about a thousand Angstroms. Due to their small size such small crystallites formed with the onset of crystallization may be considered as single domain regions (Chaughule et al ${ }^{\prime} 1983$ ). At $450^{\circ} \mathrm{C}$ these crystallites coalesce to form into narrow regions of nearly 50-100 $\mu$ length and about $10 \mu$ width (figure $3 \mathrm{~b}$ ). The hillock type crystallization products show a regular pattern elongated perpendicular to the ribbon axis. Texture Analysis System (TAS) image analysis revealed that the form factor of the regions is about 0.528 with an equivalent diameter of about $107 \mu$.

\section{$3.1 X$-ray diffraction studies}

X-ray diffraction analysis revealed a consistent amorphous structure with the samples annealed at $100,200,300$ and $400^{\circ} \mathrm{C}$. The sample annealed at $450^{\circ} \mathrm{C}$ shows a distinct crystalline diffraction pattern with $d$-values at $2.03,1.43$ and $1.17 \AA$. $A$ variety of phases such as $\alpha-\mathrm{Fe}, \mathrm{Fe}_{x} \mathrm{Co}_{1-x},(\mathrm{FeCo}) \mathrm{B},(\mathrm{FeCo})_{2} \mathrm{~B},(\mathrm{FeCo})_{3} \mathrm{~B}$ are expected (Baburaj et al 1985; Harold and Kosten 1978; Takacs et al 1975). Thus the observed XRD lines possibly belong to some of these phases. Further, distinct regions of $\alpha-\mathrm{Fe}$ or $(\mathrm{FeCo})$ type phases were not identified in the electron probe analysis (see table 2), suggesting that these could be intergrowth regions of submicron dimensions.

\subsection{Electron probe micro analysis}

Electron probe micro analysis was carried out at nearly $20,40,60$ and $80 \mu$ distance from one end to the other for several crystallites. The percentage composition of

Figure 1. Hysteresis loops of Metglas $2605 \mathrm{Co}$ parallel to the ribbon axis. Annealing temperatures (a) As obtained, (b) $100^{\circ} \mathrm{C}$, (c) $200^{\circ} \mathrm{C}$, (d) $300^{\circ} \mathrm{C}$, (e) $400^{\circ} \mathrm{C}$, (f) $450^{\circ} \mathrm{C}$. Scale: $\mathrm{X}$-axis (a) to (e) one big division $=2.5 \mathrm{Oe}$ and for $(\mathrm{f})$ it is $3.5 \mathrm{Oe}$. 



Figure 1. For caption, see page 508 

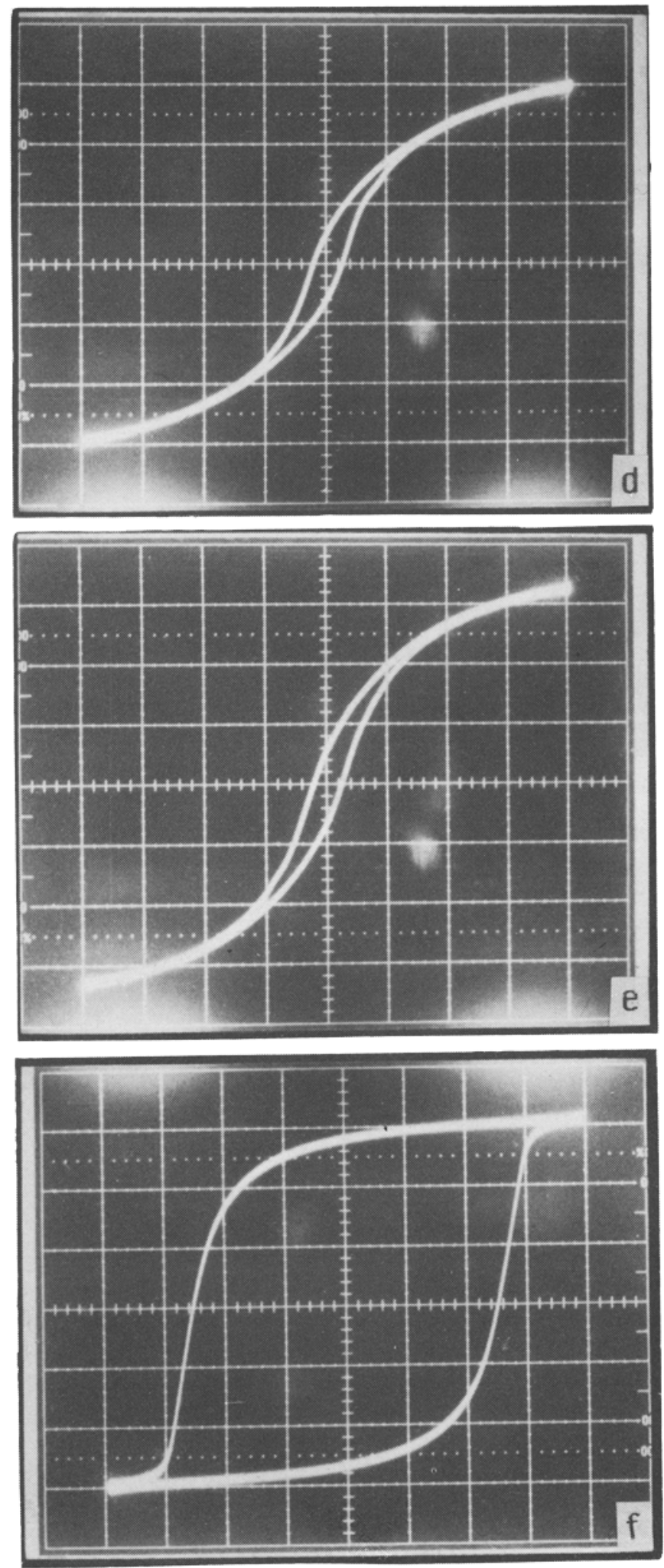

Figure 1. For caption. see page sox. 



Figure 2. For cantion, see page 573. 

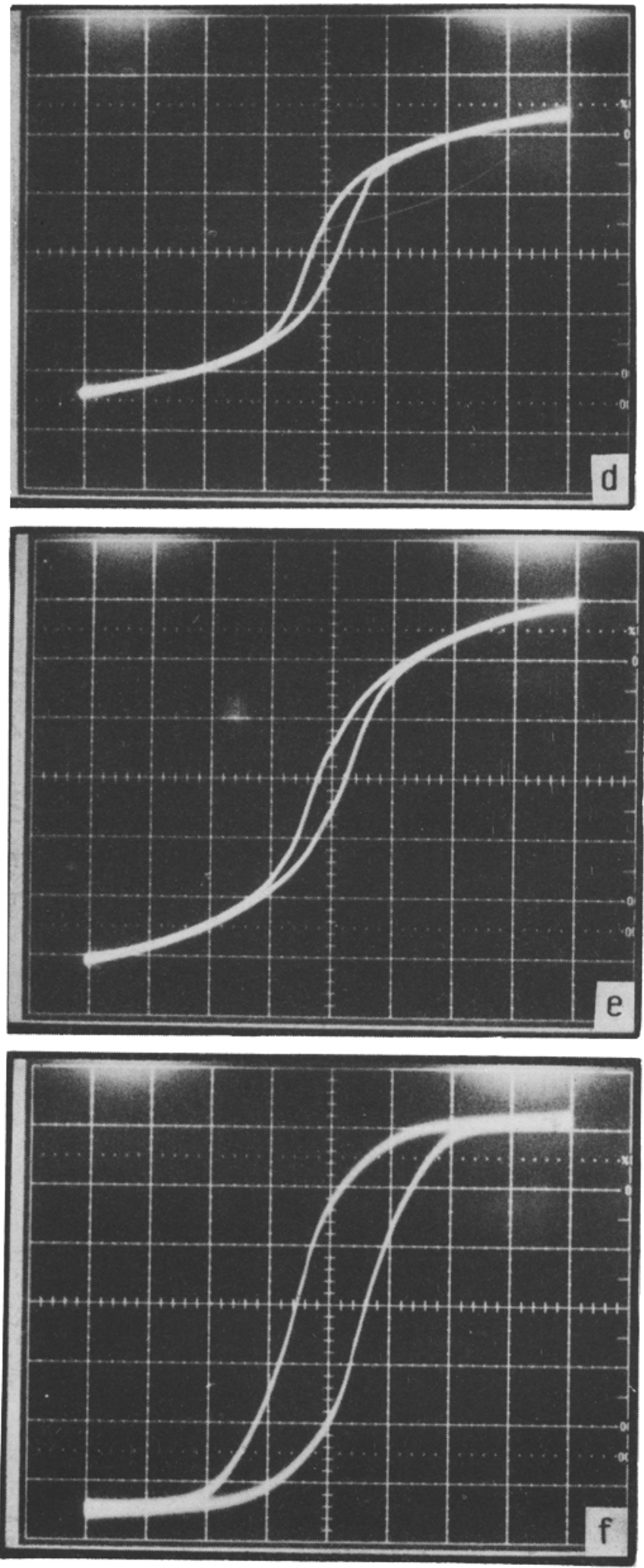

Fgure 2. For caption. see page 57.3. 
Table 1. Coercive force $H_{c}$ of Metglas 2605 in the directions parallel and perpendicular to ribbon axis.

\begin{tabular}{ccc}
\hline & \multicolumn{2}{c}{ Coercive force (Oe) } \\
\cline { 2 - 3 } Annealing & Parallel & Perpendicular \\
\hline 30 & 0.08 & 0.15 \\
100 & 0.08 & 0.15 \\
200 & 0.15 & 0.20 \\
300 & 0.30 & 0.30 \\
400 & 0.35 & 0.35 \\
450 & 8.75 & 0.60 \\
\hline
\end{tabular}

$\mathrm{Fe}, \mathrm{Co}, \mathrm{Si}$ was obtained against calibrated standards with a statistical accuracy of $0.5 \%$ of the measured value and B concentration was obtained by calculating the difference. The error estimated is about $+1 \%$ of the measured concentration (Beaman and Isasi 1972; Heinrich 1981). The results show a significant spatial variation in composition as given in table 2 . These results indicate that the crystals are boron-deficient at its centre. When there is a gradual increase in boron content away from the centre the composition around the periphery of the crystals is enriched in boron and silicon. Also, there seems to be a preferential rejection of boron at the first instance when compared to that of silicon as inferred from the $\mathrm{Si}$ enrichment at 20 and $80 \mu$ (see table 2). The crystallization process could therefore be categorized as the primary crystallization (Baburaj et al 1985; Harold and Koster 1978; Takacs et al 1975) which involved preferential displacement of boron followed by silicon into the amorphous matrix. Distinct regions of iron have not been observed suggesting that the $\alpha-\mathrm{Fe}$ phase identified in $\mathrm{x}$-ray diffraction study could be possibly present as intergrowth regions of submicron dimensions during the primary crystallization process.

\subsection{Magnetic anisotropy}

The hysteresis loops for the samples annealed at $450^{\circ} \mathrm{C}$ (figures $1 \mathrm{f}$ and $2 \mathrm{f}$ ) show enhanced anisotropic effects. $H_{c}$ increased to a value of 060 Oe perpendicular to the ribbon axis, while it is $8.75 \mathrm{Oe}$ in the parallel direction. However, the sample annealed at $400^{\circ} \mathrm{C}$ showed an $H_{c}$ value of 0.35 Oe in either direction (figures $1 \mathrm{e}$ and 2e), despite the fact that microcrystalline regions appeared due to the onset of crystallization (figure 3a). The composition of such crystallites is, therefore, expected to be nearly the same as that of the bulk. The crystallization may proceed through the formation of intergrowth structures with complex repeat sequences (Rao 1985) that are possible with the evolution of textures based on Bernal polyhedra (Finney and Wallace 1981). Further, as seen in figure $3 \mathrm{~b}$ the hillock regions are elongated perpendicular to the long axis of the ribbon. The hysteresis loops in figures if and $2 \mathrm{f}$ reveal that the hard axis of the $450^{\circ} \mathrm{C}$ annealed ribbon lies in a direction parallel to the ribbon axis. These results suggest that the intergrowth pattern is likely to occur in a direction perpendicular to the long axis of the hillock structure which, in turn, indicates that the intergrowth patterns are parallel to the ribbon axis.

Figure 2. Hysteresis loops of Metglas 2605 Co perpendicular to the ribbon axis. Annealing temperatures (a) As obtained, (b) $100^{\circ} \mathrm{C}$, (c) $200^{\circ} \mathrm{C}$, (d) $300^{\circ} \mathrm{C}$, (e) $400^{\circ} \mathrm{C}$, (f) $450^{\circ} \mathrm{C}$. Scale: $X$-axis - one big division $=2.5$ Oe for (a) to (f). 

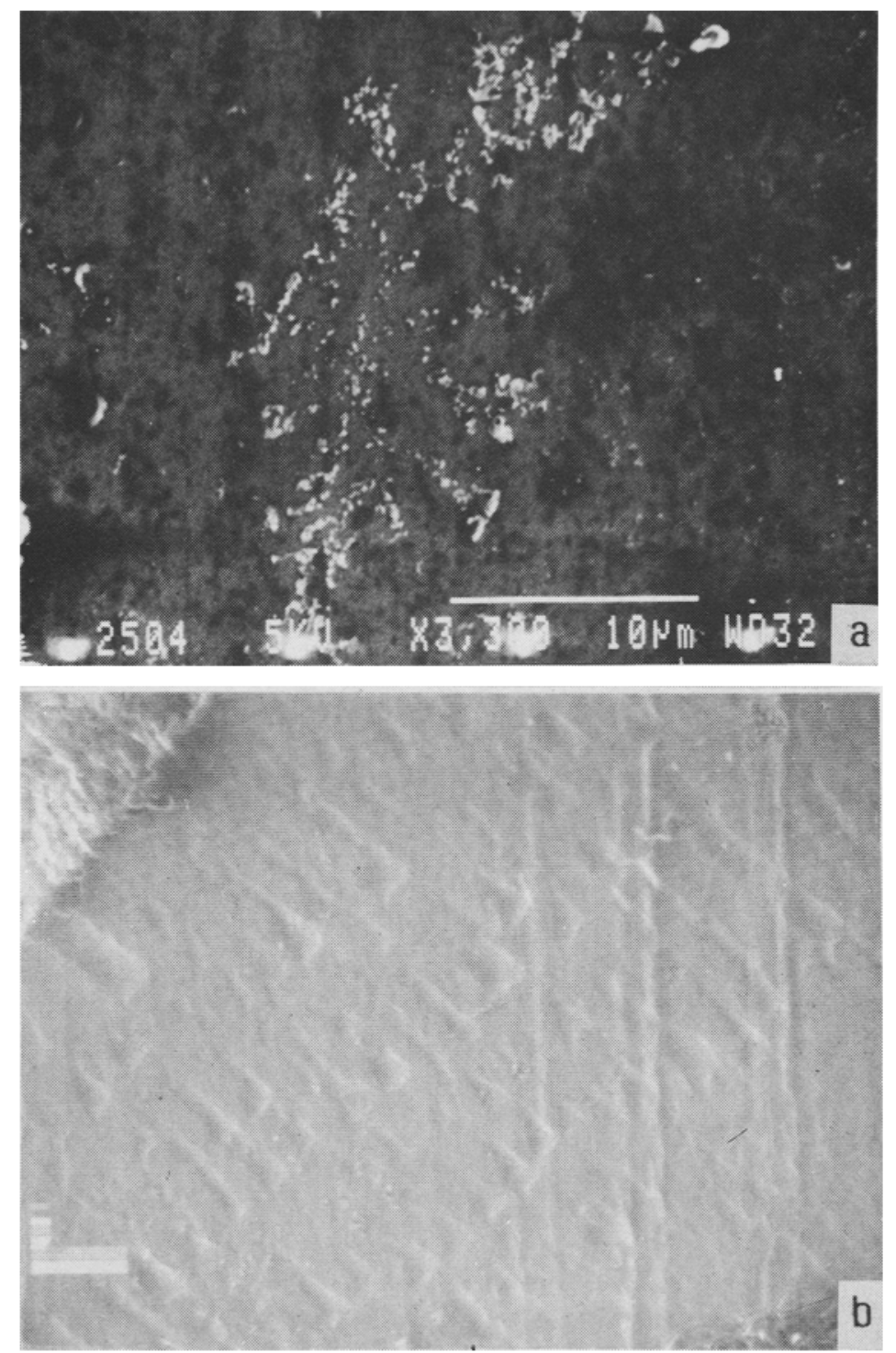

Figure 3. (a) Microcrystallites formed at $400 \mathrm{C}$. Scale: the bar represents $10 \mu$. (b) Hillock type crystallization formed at $450 \mathrm{C}$. Scale: the larger rectangle represents $100 \mu$. Arrow indicates the direction of the ribbon axis.

In accordance with the recent Mössbauer investigations (Bhatnagar et al 1985) and in the wake of preferential rejection of boron and silicon, we propose that the intergrowth regions may comprise of compositions of the form $\mathrm{Fe}_{x} \mathrm{Co}_{1-x}$, $(0 \cdot 3<x<1 \cdot 0), x-\mathrm{Fe}$ including the boron-containing phases $(\mathrm{FeCo}) \mathrm{B},(\mathrm{FeCo})_{2} \mathrm{~B}$, $(\mathrm{FeCo})_{3} \mathrm{~B}$ preferentially grown parallel to the ribbon axis. The compositions $\mathrm{Fe}_{x} \mathrm{Co}_{1-x}$, with $0.3<x<1.0$ were known to be strongly anisotropic with anisotropic constant $K$ for $\alpha-\mathrm{Fe}, \mathrm{Fe}_{0.7} \mathrm{Co}_{0.3}$ and $\mathrm{Fe}_{0.3} \mathrm{Co}_{0.7}$ being $460,-430$ and 102 respectively in units of $\times 10^{-3} \mathrm{erg} / \mathrm{cm}^{3}$ (Gray 1963). Thus the observed anisotropy may be attributed to the presence of compositions of the type $\alpha-\mathrm{Fe}, \mathrm{Fe}_{0.7} \mathrm{Co}_{0.3}$. 
Table 2. Typical composition of a crystallite from end to endEPMA data.

\begin{tabular}{lrrrr}
\hline & \multicolumn{4}{c}{ Composition from one end at $(\boldsymbol{\mu})$} \\
\cline { 2 - 5 } Element & 20 & 40 & 60 & 80 \\
\hline Fe & 73.37 & 75.99 & 75.49 & $70-10$ \\
Co & 20.16 & 20.56 & 20.36 & 19.22 \\
Si & 1.01 & 0.92 & 0.67 & 1.14 \\
B By difference & 5.46 & 2.53 & 3.47 & 9.54 \\
\hline
\end{tabular}

Note: $\mathrm{Fe}, \mathrm{Co}$ and $\mathrm{Si}$ were estimated against calibrated standards and $B$ concentration was obtained by difference. Estimated error is of the order of $\pm 1 \%$ of the measured value.

$\mathrm{Fe}_{0.3} \mathrm{Co}_{0.7}$ and $\mathrm{FeCo}$ among the various compositions that appear as intergrowth regions preferentially formed parallel to the ribbon axis.

\section{Conclusions}

(i) Thermal annealing of Metglas $2605 \mathrm{Co}$ at $450^{\circ} \mathrm{C}$ leads to pronounced magnetic anisotropy with respect to ribbon axis. (ii) The thermally-induced anisotropy of Metglas 2605 Co samples could be explained on the basis of the intergrowth patterns formed preferentially parallel to the ribbon axis leading to local compositions of the type $\alpha-\mathrm{Fe}, \mathrm{Fe}_{x} \mathrm{Co}_{1-x},(0 \cdot 3 \leqslant x \leqslant 1 \cdot 0), \mathrm{FeCo},(\mathrm{FeCo}) \mathrm{B},(\mathrm{FeCo})_{2} \mathrm{~B},(\mathrm{FeCo})_{3} \mathrm{~B}$ etc.

\section{Acknowledgements}

Sincere thanks are due to Mr V V Modak and Mr K K Karmakar for EPMA and SEM studies. We gratefully acknowledge the useful discussions with Dr S Banerjee, BARC, Bombay. AMV acknowledges his sincere regards to Dr R Krishnan, Director, NCML, for initiation, guidance and encouragement.

\section{References}

Allied Corporation 1981 Bulletin No. 15M-10/81 on Metglas electromagnetic alloys p 16

Baburaj E C, Dey G K, Patni M J and Krishnan R 1985 Scr. Metall. 19305

Beaman D R and Isasi J A 1972 Electron probe micro analysis: The fundamentals and applications, ASTM STP 506, Am. Soc. Test Mater. pp 23-28

Bhatnagat A K, Bhanuprasad B and Jagannathan R 1985 J. Appl. Phys. 573514

Chaughułe R S, Radhakrishnamurthy C, Sampathkumaran E V, Mallik S K and Vijayaraghavan R 1983 Mater. Res. Bull. 18817

Finney J L and Wallace J 1981 Proc. Fourth Int. Conf. Rapidly Quenched Metals, (ed) T Masumoto and K Suzuki Sendai Japan p 253

Gray D E (ed.) 1963 AIP Handhook (2nd edition) (New York: McGraw-Hill) Chapter 5 p 190

Haregawa R 1976 AIP Conf. Proc. 29216

Harold V and Koster U 1978 Proc. Third Int. Conf. Rapidly Quenched Metals Brighton (ed) B Cantor 1281

Heinrich K F J 1981 Electron beam micro analysis (New York: Van Nostrand) p 355

Mohri K 1984 IEEE Trans. Mag. 20942

Radhakrishnamurthy C, Lkhite S D and Sahasrabudhe P W 1978 Proc. Indian Acad. Sci. (Earth Planet. Sci.) 87A 245

Rao C N R 1985 Bull. Mater. Sci. 7155

Sasada I, Hiroike A and Harada K 1984 IEEE Trans. Mag. 20951

Suja N T, Arai K I, Shiirija Y and Masumoto T 1975 Phys. Lett. A51 121

Takacs L, Caderille M C and Vincze I 1975 J. Phy's. F5 800

Takahashi M, Ikeda N O and Miyazaki T 1976 Jpn. J. Appl. Phys. 151821 